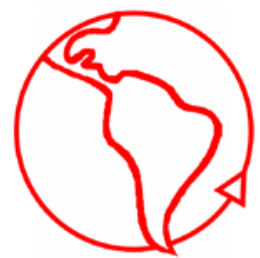

\section{La Evolución de los Mass Media}

\author{
Mass Media Evolution
}

Francisco Osorio

Facultad de Ciencias Sociales, Universidad de Chile

Resumen

El objetivo de este artículo es argumentar que la evolución de los mass media se ha entendido generalmente como evolución de las máquinas, es decir, de cambios en el hardware tendientes a criterios como más píxeles (en los televisores), menos peso (en los teléfonos móviles) o más capacidad de almacenamiento (de los correos electrónicos). Sin embargo, el artículo trata de explorar si ello es todo lo que puede decirse de la evolución de los mass media. Para lo anterior se asume la existencia de una diversidad de definiciones del concepto de evolución en ámbitos tan diversos como las ciencias sociales, la filosofía e incluso la biología.

\title{
Abstract
}

The aim of this paper is to argue that the evolution of the mass media is generally understood as the evolution of machines, ie, hardware changes aimed at criteria such as more pixels (on TV), less weight (on phones mobile) or more storage capacity (the emails). However, the article attempts to explore whether this is all it can be said about the evolution of the mass media. It assumes the existence of a variety of definitions of evolution in fields as diverse as social sciences, philosophy and even biology.

Palabras Clave: evolución; mass media; comunicación; tecnología; información

Keywords: evolution; mass media; communication; technology; information

\section{Introducción: el concepto de evolución}

Podemos partir de la afirmación que actualmente tenemos diferentes formas de entender la evolución.

En antropología existe una larga tradición en relación al concepto de evolución, puesto que las teorías evolucionistas son los primeros marcos conceptuales de esta ciencia social. Se puede citar la obra de Edward Burnett Tylor y Lewis Henry Morgan, así como de Herbet Spencer. Interesantemente, esta escuela de pensamiento asocia la evolución a la tecnología. Por ejemplo, el paso de un tipo de sociedad a otra se puede mostrar en indicadores como los materiales con que se confecciona los objetos culturales. De ahí, por ejemplo, que se hable de sociedades que evolucionaron de la Edad de la Piedra a la Edad del Hierro, para utilizar el lenguaje característico de este modelo.

En psicología, según Plotkin y Odling- Smee (1986), la teoría de la evolución en biología llamada "síntesis moderna" no puede fundamentar completamente la psicología comparada. Ellos proponen, por lo tanto, el modelo de múltiples niveles de la evolución, con el objeto de poder referirse a procesos como el aprendizaje y la cultura. Estos niveles son cuatro: biología poblacional, desarrollo individual, aprendizaje individual y evolución cultural. Este modelo posee cuatro premisas: 
1. La evolución es definida por un proceso y no por las consecuencias de ese proceso.

2. Ese proceso opera no en uno sino en todos los niveles de la o las jerarquías que describen a los sistemas vivientes.

3. El proceso que es universal a todos los niveles puede descomponerse en un conjunto de subprocesos, a los que colectivamente se les refiera como la heurística g- $p-r$.

4. La evolución se produce debido a ciertas limitaciones inherentes de los niveles inferiores para acomodar tasas rápidas de cambio.

Basándose en Campbell y Lewontin, plantean que la evolución ocurre por la acción de tres subprocesos: (1) la generación de variantes, (2) la selección de algunas de esas variantes para su transmisión y (3) la transmisión de las variantes seleccionadas. Plotkin y OdlingSmee denominan a lo anterior la heurística g- p- $r$, es decir, generación, prueba o selección y regeneración. Esta heurística tiene la propiedad de mezclar elementos conservadores (previamente seleccionados) con elementos azarosos (nuevos), un proceso que se da en el tiempo.

En este modelo, dado los argumentos 1, 2 y 3, la explicación de por qué se produce la evolución es el punto 4. Sin tomar una posición acerca de si la teoría de la evolución suscrita por Plotkin y Odling-Smee es verdadera, deseo destacar una de las propiedades de la evolución por ellos señalada: la mezcla de elementos conservadores con los azarosos.

En filosofía, Marrati (2010) propone que Henri Bergson es el más importante filósofo de la evolución. Tratando de resumir algunos puntos de su pensamiento, Marrati destaca la claridad con que Bergson descubre que la lógica de los conceptos darwinistas y neodarwinistas de la evolución es, básicamente, la lógica mecánica de la física newtoniana. Es decir, "las mutaciones de las especies son entendidas como el resultado de factores predados" (Marrati 2010:5), en otras palabras, "la emergencia de una nueva forma de vida es vista como el arreglo nuevo de viejos elementos" (Marrati 2010:5). Lo que está en juego desde un punto de vista filosófico es que lo que puede ser explicado por esta manera de pensar la evolución es, al mismo modo, una manera de predecir, dice Marrati. Sin embargo, explicación y predicción son dos elementos diferentes. En la mecánica de Newton, la trayectoria futura de los astros se puede predecir. Del mismo modo, en la evolución darwiniana, dado el conocimiento de los mecanismos de la evolución, todo ya está dado. En ambos casos, se trata de una metafísica donde la totalidad de la realidad ya está dada. Así, el cambio no es más que la reordenación de los elementos pre- existentes, concluye Marrati.

Finalmente, se puede ejemplificar el concepto de evolución desde la filósofa Parisi, para quien "si la evolución es entendida como un proceso, los procesos deben ser concebidos como hechos de formas. Whitehead [dice Parisi] señala que no hay procesos de formas, sino formas de procesos. Desde este punto de vista, ninguna forma evolutiva puede durar para siempre. El llegar a ser de una forma es eterna, no porque la misma forma perdure por siempre, sino porque una vez que la forma perezca, implica el advenimiento de una nueva" (2010:149).

Frente a estas diversas formas de entender la evolución, entonces, ¿cómo podríamos entender el objetivo de este artículo que es reflexionar sobre la evolución de los mass media?, ¿qué sería una evolución de los mass media? Volveré sobre estos autores más adelante, pero por ahora deseo introducir el tema de la tecnología. 


\section{Tres ejemplos de mass media}

Antes de responder estas preguntas, se podrían examinar tres ejemplos concretos: la televisión, el correo electrónico y la telefonía móvil (o celular).

\section{La televisión}

Los televisores, han pasado de la imagen en blanco y negro al color. Del mismo modo, han cambiado sus imágenes de regular calidad a la alta definición. Incluso más, sabemos que lo que hoy entendemos por alta definición es una muestra o breve ventana en comparación a la tecnología por venir que, hoy en versión de prueba, cuadruplica la cantidad de píxeles en las imágenes televisivas y ello es sólo el comienzo. Pensemos en el cambio de la imagen bidimensional del televisor a la tridimensional, que por el momento nos tiene usando lentes especiales para conseguir el efecto. También podemos ver cambios en los televisores, que ahora permiten ver canales de YouTube, navegar por Internet, conectar un Play Station y, por cierto, ver el noticiero central. Podríamos decir, entonces, que la televisión ha evolucionado y que lo continúa haciendo.

\section{El correo electrónico}

Si nos preguntamos en qué sentido el correo electrónico ha evolucionado, podríamos decir que para una persona común y corriente le sería un poco complicado responder. Una posibilidad sería que hemos usado diferentes versiones de Microsoft Outlook a lo largo del tiempo y que ello es un ejemplo de evolución. Sin embargo, eso no responde a nuestra pregunta. Ahora usamos programas en la Web como Yahoo Mail o Google Mail, así como Hotmail, pero todos ellos son programas que han cambiado a lo largo de los años para mandar correos electrónicos, que incorporan cada vez mayores funcionalidades. Sin embargo, y esto es lo interesante, el correo electrónico como concepto es anterior a lo que hoy conocemos como Web y, por lo tanto, la estructura básica de un email es el mismo desde 1970. Eso implica que un correo imaginario enviado en la década de 1970 sería fácilmente recibido en la década del 2010.

Hoy en día, Facebook tiene un sistema de emails (Daily Mail 2010). Si hacemos caso a las declaraciones en la prensa, estaríamos ante la muerte del email como lo conocemos y el surgimiento de un nuevo sistema: Facebook Mail. Sin embargo, no parece todavía que sea el caso. Sigue siendo un sistema de correo electrónico, sólo que tiene ciertas particularidades. Entre ellas el estar dentro de Facebook, por lo tanto, en teoría no hay spam, dado que sólo se pueden recibir correos de los contactos o "amigos" como se dice en Facebook. No tiene "asunto" o "subject", que es una característica que mucha gente odia cuando escribe correos. Está más bien pensado para acercarse a la comunicación instantánea e integrar lo que ha sido el correo electrónico con el muro (wall), las actualizaciones en línea y mensajes de texto, entre otros a futuro. La pregunta es si esto es un ejemplo de la evolución del email.

Google también nos puede ayudar a reflexionar sobre qué sería una evolución del email. Google Wave fue un proyecto que también en su momento fue catalogado como el futuro del email, pero hoy en día no existe. Las personas que lo usaron decían que estaba adelantado a su época. Pero eran muchos más las personas que ni siquiera sabía que existía Google Wave. También era un sistema que combinaba email con mensajería instantánea, pero además tenía herramientas de colaboración en línea para trabajar en documentos. Algunas de esas ideas han pasado en una versión menor a Google Mail, por ejemplo, con Google Talk, pero Wave incluso permitía ver lo que se escribía a medida que la otra persona lo hacía, no como ahora en que hay que esperar que la otra persona presione enter antes de ver el mensaje. Así entonces, podríamos ver aquí el caso de un ejemplo de evolución pero, usando el lenguaje de la biología, de un organismo que no fue 
seleccionado por el ambiente, lo cual nos permitiría hablar que sí existe la evolución del email.

\section{La telefonía móvil}

Un ejemplo de mass media con el podríamos trabajar es la telefonía móvil, también conocida como telefonía celular. Tiene varios orígenes, dependiendo de cómo se considere el principio básico de transmisión. Según Jon Agar (2003:23) la comunicación telefónica por ondas es algo que ya hacían los barcos en la Segunda Guerra Mundial y la primera conceptualización de hacer celdas (o células) para transmitir la voz entre una y otra celda hasta llegar al destinatario es de los años 1950. Sin embargo, para la mayoría de nosotros, lo que entendemos por telefonía móvil no vendrá sino hasta el primer teléfono reconocible masivamente como tal, es decir, el modelo DynaTAC 8000x de Martin Cooper de 1983. Para nosotros Cooper es el padre de la telefonía móvil. Ahora bien, veamos cómo ha evolucionado este mass media. Si consideremos el modelo DynaTAC 8000x y lo comparamos con el iPhone 4, podemos notar claramente una evolución en los siguientes aspectos. Se ha reducido el peso, desde los $793 \mathrm{~g}$ a $137 \mathrm{~g}$; en términos de dimensiones de $25 \mathrm{~cm}$ en su lado más largo a $11 \mathrm{~cm}$; de ser un aparato que trasmitía sólo la voz a uno que es un computador con miles de programas. Si se mostrara un video en que cada segundo fuera un modelo popular de teléfonos móviles, veríamos cómo se han reducido de tamaño, cómo se han refinado sus diseños, cómo se han eliminado los botones en función de pantallas táctiles, en fin, es clara la idea.

Todo lo anterior tiene muchas simplificaciones y muchos supuestos. Primero, no hay razón alguna que justifique que el iPhone 4 es la cúspide de la evolución. Es sólo un aparato seleccionado por su efectiva campaña publicitaria y que permite ejemplificar el tema dado que muchas personas lo conocen. Un lector actual tendría que buscar en Google el modelo DynaTAC 8000x para entender a qué me estoy refiriendo. Si este artículo es leído en veinte años, es posible que ese lector se pregunte qué es eso de Google y a qué se referían con eso de los iPhone. Segundo, la descripción hace referencia al hardware pero no al software. Una manera de describir esta idea es decir que nos hemos desplazado desde el Feature Phone al Smartphone. En otras palabras, del teléfono para transmisión de voz al teléfono que transmite y recibe datos digitalizados permitiendo la navegación por Internet, programas de juegos, agendas, fotografía, video y un largo etcétera. Incluso la idea de que los teléfonos tengan sistemas operativos es difícil de entender en las personas hoy en día.

Volvamos a Martin Cooper. El creador de los que hoy entendemos por teléfonos móviles piensa que a futuro estos ni siquiera existirán en forma reconocible, más bien estarán integrados a nuestras orejas conectados a poderosos computadores (BBC 2010). El tampoco usa un iPhone 4 (en realidad lo usó), sino que todo aparato que salga al mercado, pues le interesa conocer cómo funcionan todos ellos.

Sin embargo, hay algo que no ha evolucionado: la idea básica de la red celular. Una idea que no debe confundirse es el paso de $2 \mathrm{G}$, EDGE, $3 G$ y $4 \mathrm{G}$, pero ello son "espacios" o "caminos" por donde transitan los datos en un espectro de ondas. Se podría hablar de una evolución ahí, en el sentido de que cada vez se puede navegar más rápido por Internet (mayor capacidad de transmisión de datos). Sin embargo, el punto es que la arquitectura básica de la red es la misma: por antenas celulares que se comunican entre sí y que permiten que los datos se desplacen entre ellas hacia una red fija de telefonía u otra red de telefonía móvil.

\section{Evolución y Mass Media}

Esto nos permite señalar que el concepto de evolución es más fácil de asociarlo a dispositivos tecnológicos (máquinas) que al concepto sobre el cual descansa la telefonía 
móvil (transmisión de datos entre celdas). Del mismo modo, la arquitectura inicial del correo electrónico sigue siendo la misma y lo que ha cambiado son los programas que mandan y reciben los correos, integrados ahora a otras funciones, como mensajería instantánea y calendarios (por ejemplo, desde algunos programas de correo se puede coordinar una reunión mediante las opciones de administración de calendarios). La televisión es la misma desde el siglo pasado. Que podamos ver televisión en el computador ejemplifica precisamente el punto. Cuando es en vivo, es la misma transmisión televisiva, sólo que ahora se puede ver en el dispositivo llamado computador. De manera similar, que la radio se pueda escuchar en algunos teléfonos celulares no cambia el principio básico de la radio.

En otras palabras, nos es claro entender que los aparatos (dispositivos) han evolucionado. La pregunta es si ello es todo lo que puede decirse de la evolución de los mass media: la evolución está en la máquina.

Una pista podría estar en un concepto que se ha empleado con fuerza desde la década de 1990: convergencia. Por lo menos en el ámbito de los mass media el concepto hace referencia a ejemplos como el siguiente: históricamente el teléfono residencial era una tecnología independiente de la radio, independiente del cine, la televisión y la prensa. Hoy en día en el teléfono móvil convergen la telefonía fija, la radio, el cine, la televisión y la prensa. Incluso más, hoy en algunos teléfonos móviles se puede hablar por Skype.

En el año 1995 se creó una revista precisamente con el nombre de convergencia. Su subtítulo es "revista internacional de investigación en tecnologías de new media". El concepto de new media ha venido a reemplazar el de mass media que he empleado aquí. De acuerdo a su primera editorial, la revista Convergencia tiene como propósito servir de foro interdisciplinario a la investigación en las nuevas tecnologías mediales que están todavía evolucionando. Esto es interesante, pues la editorial declara al inicio que el campo de estudio está en permanente evolución y, por lo tanto, la revista desea extender una invitación a la observación permanente de todos los nuevos productos que entran al mercado y cómo ellos producen efectos en la sociedad a nivel global y local.

Sin embargo, otros investigadores como W. Russell Neuman (2010) nos plantean que hay que tener cuidado con el concepto de convergencia, en el sentido que se lo entienda como el futuro en esta evolución de los medios. Como dice Neuman, todos los años vienen diciendo que la prensa está muerta y, sin embargo, ahí está desde hace siglos.

Por cierto, no hay claridad en lo que se entiende por evolución de los medios. Por ejemplo, Neuman (2010:12) entiende el concepto de evolución de los medios de una manera restrictiva, es decir, como un modo de análisis a través de conceptos como equivalencia funcional (cuando un nuevo medio llega y sirve mejor una función particular, el uso del medio dominante anterior declina), el principio de consistencia relativa (el porcentaje de los ingresos gastados en el consumo de medios en Estados Unidos se ha mantenido relativamente constante en el siglo XX), la paradoja del flujo de comunicación (aunque la capacidad de computación se incrementa según la ley de Moore, los límites humanos siguen siendo los mismos) y la diversidad de los medios (un mercado diverso de ideas es mejor satisfecho con un patrón diverso de propiedad de los medios).

Si se revisa la literatura sobre la evolución de los medios, generalmente se encuentra la versión que ya hemos descrito, es decir, asociar evolución a máquinas. Es decir, cómo hemos evolucionado de la imprenta de Gutenberg al Amazon Kindle. Casi cualquier medio que se considere es abordado desde esta perspectiva. Por ejemplo "The evolution of the blogger: Blogger considerations of public relations- sponsored content in the blogosphere" (Smith 2010) y "The world is a phone booth: The American response to mobile phones, 1981- 2000" (Arceneaux 2005). 
Pero lo pregunta vuelve: ¿es eso todo lo que podemos decir de la evolución de los medios? $\mathrm{Si}$ examinamos la propuesta de Plotkin y Odling-Smee (1986), podemos considerar algunos de sus elementos de análisis (dado que ellos están tratando de fundamentar una psicología comparada) e inferir para el caso de los medios lo siguiente: lo que sea la evolución de los medios es un proceso, el cual se descompone de subprocesos bajo la heurística g- p-r. El primer paso (g) se refiere a la generación de variantes (por ejemplo, teléfonos móviles que tienen dos sim card en vez del teléfono tradicional que sólo tiene una tarjeta que identifica la empresa telefónica que presta el servicio mediante un número de teléfono almacenado en ella). El segundo paso (p) es una prueba o selección de algunas de esas variantes para su transmisión (por ejemplo, hay países o grupos que encuentran muy necesario esta característica de tener dos tarjetas en un mismo teléfono, mientras que otros lo encuentran absolutamente innecesario). El tercer paso ( $r$ ) es la regeneración, es decir, la transmisión de estas variantes seleccionadas (en este ejemplo, teléfonos con esta características son preferidos en ciertos mercados a los teléfonos tradicionales). En conclusión, la evolución es una mezcla de elementos conservadores (ya seleccionados) con elementos azarosos (nuevas opciones o posibilidades), que se da en el tiempo. La explicación de por qué se produce la evolución, de acuerdo a estos autores, tiene que ver con limitaciones en una versión de la tecnología (podríamos decir así) para reaccionar a tasas rápido de cambio.

Todo lo anterior, por cierto, son enormes saltos conceptuales que no pueden sustentarse literalmente. Sólo estamos justificados para usarlas como metáforas, dado que hay muchos argumentos que no se aplican. El más obvio de todos ellos es que la teoría de la evolución trata con sistemas vivos, mientras que los medios no lo están. Dicho lo anterior, la propuesta de Plotkin y Odling-Smee hace sentido aplicada al ejemplo y posee interesantes elementos para pensar una evolución de los medios.

En línea con lo anterior, la interpretación que hace Marrati (2010) de la filosofía de Bergson también apunta a que la teoría evolutiva clásica ocupa una metafísica donde la totalidad de la realidad ya está dada, es decir, donde el cambio es reordenación de elementos ya existentes. Justamente el aporte de Bergson y también de Plotkin y OdlingSmee está en la introducción del concepto de la novedad frente a lo existente, siendo la evolución un proceso que combina en el tiempo, de una cierta manera, lo existente con lo nuevo. Finalmente, la propuesta de Parisi (2010), basado en la filosofía de Whitehead, acentúa el concepto de proceso y, por lo tanto, infiere que lo que sean las formas evolutivas es, siempre, el advenimiento de una nueva forma.

Estas propiedades de la evolución también nos pueden ayudar a pensar la evolución de los medios (ya sean los mass media o los new media). Por ejemplo, permite entender la permanente transformación de una tecnología de la comunicación, como por ejemplo el correo electrónico, que desde un punto de vista conservador sigue siendo el mismo (su idea fundamental no ha cambiado desde la década de 1970), pero como un proceso es, al mismo tiempo, diferente. Esta diferencia está dada por la incorporación de elementos nuevos: uso de calendarios, chat, almacenamiento online de la información permanente, entre otros elementos.

La televisión es la misma, en un sentido, pero se puede entender su evolución como la incorporación en este medio de elementos nuevos frente a lo existente, por ejemplo, la introducción de la imagen 3D, la calidad de imagen en HD (High Definition), la posibilidad de ser vista en computadores por transmisión en Internet, en fin, un proceso en el tiempo de mezcla de elementos antiguos con los nuevos. En todo ello, la selección juega un importante rol, dado que no sabemos todavía si la televisión 3D realmente será aceptada por el público. Ya se conoce que algunos géneros funcionan (películas de acción), pero no las comedias románticas (o los sitcom). 
La evolución de los medios, entonces, se puede abordar con una visión más amplia que la evolución de la máquina. Para pensar la evolución de los medios se pueden ocupar los siguientes conceptos: proceso, conservación, novedad, tiempo, selección, cambio y forma. Lo que se busca, en definitiva, es el enriquecimiento del análisis mediante el recurso a la exploración que la filosofía y las ciencias sociales han dado sobre la evolución biológica. Todos estos esfuerzos analíticos, entonces, pueden estar disponibles para nosotros para estar atentos a las continuas modificaciones de las tecnologías de la información y comunicación en relación con la sociedad y la cultura de nuestro tiempo. RM

\section{Bibliografía}

Arceneaux, N. (2005). The World is a Phone Booth: The American Response to Mobile Phones, 1981-2000. Convergence: The International Journal of Research into New Media Technologies, 11 (2), 23-31.

BBC News. (2010). Meet Marty Cooper - the inventor of the mobile phone. 23 April. http:// news.bbc.co.uk/2/ hi/ programmes/click_online/8639590.stm (Consultado el 23 Abril de 2010)

Dialy Mail. (2010). 'Email is dead' claims Facebook founder Mark Zuckerberg as he launches 'Google Gmail killer' messaging Service. http:// www. dailymail.co.uk/ sciencetech/ article- 1329979/ Facebook- email- MarkZuckerberg- launches- Google- Gmail-killer.html\#ixzz1MMvtq1Ys (Consultado 16 Noviembre de 2010).

Marrati, P. (2010). The natural cyborg: The stakes of Bergson's philosophy of evolution. The Southern Journal of Philosophy, (48), 3- 17.

Neuman, W. R. (2010). Media, technology, and society: Theories of media evolution. Ann Arbor: University of Michigan Press.

Parisi, L. (2010). Event and evolution. The Southern Journal of Philosophy, (48), 147- 164.

Plotkin, H.C. \& Odling- Smee, F.J. (1986). Un modelo de la evolución de múltiples niveles y sus implicaciones para la psicología comparada. Revista Latinoamericana de Psicología, 18(2), 183-197.

Smith, B.G. (2010). The evolution of the blogger: Blogger considerations of public relations- sponsored content in the blogosphere. Public Relations Review, 36(2), 175- 177.

\section{Sobre el autor}

Francisco Osorio obtuvo su grado de Doctor en Filosofía, mención Epistemología en la Universidad de Chile. Realizó sus estudios postdoctorales en la Universidad Sheffield Hallam de Manchester (Inglaterra). Actualmente es director de la prestigiosa revista electrónica sobre Epistemología de las Ciencias Sociales "Cinta de Moebio".

fosorio@uchile.cl

\section{Contacto}

Facultad de Ciencias Sociales, Universidad de Chile

Cap. Ignacio Carrera Pinto 1045

Ñuñoa, Santiago 
Francisco Osorio - La Evolución de los Mass Media

Recibido: Julio/2011

Aceptado: Agosto/2011

Artículo disponible en: http:// www.facso.uchile.cl/publicaciones/mad/25/ osorio03.pdf 